\title{
Satellite observation of atmospheric methane: intercomparison between AIRS and GOSAT TANSO-FTS retrievals
}

\author{
Mingmin Zou ${ }^{1}$, Xiaozhen Xiong ${ }^{2,3}$, Naoko Saitoh ${ }^{4}$, Juying Warner ${ }^{5}$, Ying Zhang ${ }^{1}$, Liangfu Chen ${ }^{1}$, Fuzhong Weng ${ }^{3}$, \\ and Meng $\operatorname{Fan}^{1}$ \\ ${ }^{1}$ The State Key Laboratory of Remote Sensing Science, Institute of Remote Sensing and Digital Earth, \\ Chinese Academy of Sciences, Beijing 100101, China \\ ${ }^{2}$ Earth Resources Technology, Inc., Laurel, MD, USA \\ ${ }^{3}$ NOAA Center for Satellite Applications and Research, College Park, MD 20740, USA \\ ${ }^{4}$ Center for Environmental Remote Sensing, Chiba University, 1-33 Yayoi-cho, Inage-ku, Chiba, Japan \\ ${ }^{5}$ Department of Atmospheric and Oceanic Science, University of Maryland, College Park, MD 20740, USA
}

Correspondence to: Meng Fan (fanmeng@radi.ac.cn) and Ying Zhang (zhangying01@ @adi.ac.cn)

Received: 10 August 2015 - Published in Atmos. Meas. Tech. Discuss.: 14 October 2015

Revised: 5 July 2016 - Accepted: 11 July 2016 - Published: 3 August 2016

\begin{abstract}
Space-borne observations of atmospheric methane $\left(\mathrm{CH}_{4}\right)$ have been made using the Atmospheric Infrared Sounder (AIRS) on the EOS/Aqua satellite since August 2002 and the Thermal and Near-infrared Sensor for Carbon Observation Fourier Transform Spectrometer (TANSOFTS) on the Greenhouse Gases Observing Satellite (GOSAT) since April 2009. This study compared the GOSAT TANSOFTS thermal infrared (TIR) version $1.0 \mathrm{CH}_{4}$ product with the collocated AIRS version $6 \mathrm{CH}_{4}$ product using data from 1 August 2010 to 30 June 2012, including the $\mathrm{CH}_{4}$ mixing ratios and the total column amounts. The results show that at 300-600 hPa, where both AIRS and GOSAT-TIR $\mathrm{CH}_{4}$ have peak sensitivities, they agree very well, but GOSAT-TIR retrievals tend to be higher than AIRS in layer $200-300 \mathrm{hPa}$. At $300 \mathrm{hPa}$ the $\mathrm{CH}_{4}$ mixing ratio from GOSAT-TIR is, on average, $10.3 \pm 31.8 \mathrm{ppbv}$ higher than that from AIRS, and at $600 \mathrm{hPa}$ GOSAT-TIR retrieved $\mathrm{CH}_{4}$ is $-16.2 \pm 25.7 \mathrm{ppbv}$ lower than AIRS $\mathrm{CH}_{4}$. Comparison of the total column amount of $\mathrm{CH}_{4}$ shows that GOSAT-TIR agrees with AIRS to within $1 \%$ in the mid-latitude regions of the Southern Hemisphere and in the tropics. In the mid to high latitudes in the Northern Hemisphere, comparison shows that GOSAT-TIR is $\sim 1-2 \%$ lower than AIRS, and in the high-latitude regions of the Southern Hemisphere the difference of GOSAT from AIRS varies from $-3 \%$ in October to $+2 \%$ in July. The difference between AIRS and GOSAT TANSO-FTS retrievals is mainly due to the difference in retrieval algorithms and in-
\end{abstract}

struments themselves, and the larger difference in the highlatitude regions is associated with the low information content and small degrees of freedom of the retrieval. The degrees of freedom of GOSAT-TIR retrievals are lower than that of AIRS, which also indicates that the constraint in GOSAT-TIR retrievals may be too strong. From the good correlation between AIRS and GOSAT-TIR retrievals and the seasonal variation they observed, we are confident that the thermal infrared measurements from AIRS and GOSAT-TIR can provide valuable information to capture the spatial and temporal variation of $\mathrm{CH}_{4}$, especially in the mid-upper troposphere, in most periods and regions.

\section{Introduction}

As the third most important greenhouse gas after carbon dioxide $\left(\mathrm{CO}_{2}\right)$ and water vapor, atmospheric methane $\left(\mathrm{CH}_{4}\right)$ has a lifetime of about 12 years and is more effective in absorbing long-wave radiation, as its radiative forcing is about 26 times more than that of $\mathrm{CO}_{2}$ on a 100-year time horizon and accounts for $32 \%$ of the total anthropogenic well-mixed greenhouse gas radiative forcing (IPCC, 2013). Mainly due to the impact of human activities, the concentration of $\mathrm{CH}_{4}$ in the atmosphere has increased from the pre-industrial levels of about $700 \mathrm{ppb}$ to recent levels of about 1800-1900 ppb. 
Ground-based networks, such as NOAA/ESRL/GMD (National Oceanic and Atmospheric Administration, Earth System Research Laboratory, Global Monitoring Division), provide measurements of $\mathrm{CH}_{4}$ at the surface with a long temporal record but for a limited number of stations, primarily in the Northern Hemisphere. Aircraft measurements from NOAA/ESRL/GMD (Tans, 2009) and ARIES operated on UK FAAM aircraft (Illingworth et al., 2014), as well as some research campaigns, provide sparse, intermittent measurements of $\mathrm{CH}_{4}$ vertical profiles. Because of a limited number of in situ measurements in time and space domain, the quantification of $\mathrm{CH}_{4}$ emissions from different sources and in different regions still remains largely uncertain. In recent years, space-borne measurements of $\mathrm{CH}_{4}$ from satellites have become available, such as the measurements using the thermal infrared (TIR) sensors, which include the Atmospheric InfraRed Sounder (AIRS) on NASA/Aqua (Aumann et al., 2003; Xiong et al., 2008, 2010a, b), the Tropospheric Emission Spectrometer (TES) on NASA/Aura (Payne et al., 2009; Wecht et al., 2012; Worden et al., 2012), and the Infrared Atmospheric Sounding Interferometer (IASI) on METOPA and METOP-B (Xiong et al., 2013; Crevoisiter et al., 2009, 2013; Razavi et al., 2009). Measurements using the Near-Infrared (NIR) sensors include the SCanning Imaging Absorption spectroMeter for Atmospheric CHartographY (SCIAMACHY) instrument onboard ENVISAT for 20032009 (Frankenberg et al., 2008, 2011), and the Thermal And Near infrared Sensor for carbon Observation (TANSO) onboard the Greenhouse gases Observation SATellite (GOSAT) from 2009 to present (Yokota et al., 2009; Paker et al., 2011; Schepers et al., 2012; Saitoh et al., 2012). These space-borne measurements provide complementary data sources to surface observations for monitoring atmospheric $\mathrm{CH}_{4}$ with a large spatial and temporal coverage.

AIRS, GOSAT TANSO-FTS TIR and other thermal infrared sensors, including TES and IASI, have been used to retrieve atmospheric $\mathrm{CH}_{4}$, and these data have been used for analyzing the spatial and temporal variation of $\mathrm{CH}_{4}$, so an intercomparison of these two different products from AIRS and GOSAT will provide useful information to users to better understand the characteristics of these two products. Validation with AIRS V6 $\mathrm{CH}_{4}$ data was recently made using $\sim 1000$ aircraft profiles (Xiong et al., 2015), and the results show the mean biases of AIRS $\mathrm{CH}_{4}$ at layers 343-441 and 441$575 \mathrm{hPa}$ are -0.76 and $-0.05 \%$ and the RMSEs are 1.56 and $1.16 \%$, respectively. Some correlation of the retrieval error with degrees of freedom (DOFs) was also found, and the errors in the spring and in the high northern latitudes are larger than in other seasons or regions. A comparison between the GOSAT TIR methane retrievals with those of AIRS therefore represents an indirect validation of the GOSAT data with in situ measurements. Section 2 provides a brief introduction of these two instruments, their retrieval algorithms and the data used in this study. Section 3 shows the comparison results, which include the comparison of the retrieved profiles, the information content characterized by the DOFs and the averaging kernels from these two instruments. Both the retrieved $\mathrm{CH}_{4}$ mixing ratios and the total column amounts in different seasons and different regions are compared. A summary and conclusion are given in Sect. 4.

\section{$2 \mathrm{CH}_{4}$ retrievals from AIRS and GOSAT-TIR}

\subsection{AIRS instrument and the retrieval algorithm description}

AIRS on the EOS/Aqua satellite was launched in polar orbit (13:30 LST, ascending node) in May 2002. It has 2378 channels covering 649-1136, $1217-1613$ and $2169-2674 \mathrm{~cm}^{-1}$ at high spectral resolution $\left(\lambda / \Delta \lambda=1200, \sim 0.5 \mathrm{~cm}^{-1}\right)$ (Aumann et al., 2003), and the noise equivalent differential temperature $(\mathrm{Ne} \Delta T)$ at a reference temperature of $250 \mathrm{~K}$ ranges from $0.14 \mathrm{~K}$ in the $4.2 \mu \mathrm{m}$ region (the lower tropospheric sounding) to $0.35 \mathrm{~K}$ in the $15 \mu \mathrm{m}$ region (the upper tropospheric sounding). The spatial resolution of AIRS is $13.5 \mathrm{~km}$ at nadir, and in a $24 \mathrm{~h}$ period, AIRS nominally observes the complete globe twice per day. In order to retrieve $\mathrm{CH}_{4}$ in both clear and partially cloudy scenes, nine AIRS fields of view (FOVs) within the footprint of the Advanced Microwave Sounding Unit (AMSU) are used to derive a single cloud-cleared radiance spectrum in a field of regard (FOR). The cloud-cleared FOR radiance spectrum is then used to retrieve profiles with a spatial resolution of approximately $45 \mathrm{~km}$ (Aumann et al., 2003). The atmospheric temperature profiles, water vapor profiles, surface temperatures and surface emissivity are required as inputs to compute the radiances in the $\mathrm{CH}_{4}$ absorption band. The differences between the computed radiances and the AIRS measured radiances for clear pixels or the derived cloud-cleared FOR radiances for partially cloudy pixels are used to derive $\mathrm{CH}_{4}$ profiles based on optimal estimation method. A total of $50-60 \mathrm{CH}_{4}$ absorption channels near the $7.66 \mu \mathrm{m}$ band are selected for the retrievals. The AIRS retrieval algorithm is a sequential retrieval method with multiple steps, in which the temperature and water vapor profiles are retrieved using appropriate channels in previous steps. Thus the quality of the $\mathrm{CH}_{4}$ retrievals depends on the whole AIRS science team's efforts in improving the temperature and moisture profiles as well as surface temperature and emissivity products. More details of AIRS $\mathrm{CH}_{4}$ retrievals in its most recent version, i.e., version 6 (V6), can be found in Xiong et al. (2015).

\subsection{GOSAT TANSO-FTS TIR and the retrieval algorithm description}

GOSAT was launched into a sun-synchronous orbit on 23 January 2009 by an H-IIA launch vehicle. GOSAT is on a $666 \mathrm{~km}$ orbit and has a 3-day revisit orbit cycle and a 12day operation cycle. The local solar time is 13:00 $\pm 15 \mathrm{~min}$. GOSAT carries two sensors: the TANSO-FTS and the 
TANSO-CAI. The IFOV of the TANSO-FTS is $10.5 \mathrm{~km}$ in diameter, and that of the TANSO-CAI is $0.5-1.5 \mathrm{~km}$ in diameter. TANSO-FTS on board GOSAT makes global observations, including both nadir and off-nadir measurements, of approximately 56000 ground points every 3 days. TANSO-FTS consists of four spectral bands: Band 1 (0.75$0.78 \mu \mathrm{m})$, Band $2(1.56-1.72 \mu \mathrm{m})$, Band $3(1.92-2.08 \mu \mathrm{m})$, and Band $4(5.5-14.3 \mu \mathrm{m})$. The spectra resolution of Band 4 is $0.2 \mathrm{~cm}^{-1}$ and its signal-to-noise ratio (SNR) averages approximately 300 at Band 4 for a blackbody temperature of 280 K. (Kuze et al., 2009, 2012; Saitoh et al., 2009). More information on TANSO-FTS TIR and its calibration can be found in Kuze et al. (2012). In the TIR retrieval algorithm version 1.0, all the channels in 7.3-8.8 $\mu \mathrm{m}$, which include both the $\mathrm{CH}_{4}$ and $\mathrm{N}_{2} \mathrm{O}$ absorption bands, are used for $\mathrm{CH}_{4}$ retrieval. In the TANSO-FTS TIR V1.0 $\mathrm{CH}_{4}$ retrieval processing, we simultaneously retrieve $\mathrm{H}_{2} \mathrm{O}, \mathrm{N}_{2} \mathrm{O}, \mathrm{O}_{3}$, and temperature other than $\mathrm{CH}_{4}$. We also simultaneously derive surface temperature and surface emissivity as a correction parameter of spectral bias inherent in TANSO-FTS TIR V161.160 $\mathrm{L} 1 \mathrm{~B}$ spectra in the same manner as $\mathrm{CO}_{2}$ retrieval (Saitoh et al., 2016).The retrieval algorithm is a non-linear maximum a posteriori method with linear mapping (Rodgers, 2000). The a priori $\mathrm{CH}_{4}$ profiles used in the retrieval are taken from the National Institute for Environmental Studies (NIES) transport model (Maksyutov et al., 2008; Saeki et al., 2013). Profiles of temperature and water vapor required for the retrieval are taken from the Japan Meteorological Agency Grid Point Values (JMA-GPV) data set. Values of surface emissivities are estimated by a linear regression analysis using the Advanced Spaceborne Thermal Emission Reflection Radiometer (ASTER) spectral library (Baldridge et al., 2009), the information of land cover, sea ice, wind speed, and the vegetation index derived from the TANSO-Cloud and Aerosol Imager (CAI). Surface temperatures are estimated from the TANSO-FTS TIR spectra in the window region. The signalto-noise ratios (SNR) of TANSO-FTS at around the 7-8 $\mu \mathrm{m}$ band are estimated to be $70-100$, and the measurement covariance matrix used in the retrieval is based on the SNR values. The footprint of GOSAT-TANSO is $10.5 \mathrm{~km}$ in diameter, and the number of scan points of GOSAT in cross-track direction is five before July 2010 and three thereafter.

\subsection{Data used}

This study is made using the standard products of both sensors. GOSAT TANSO-FTS TIR Level $2 \mathrm{CH}_{4}$ profile products in version 01.01 for a 2 -year period from $\mathrm{Au}$ gust 2010 to June 2012 are used, and the data during this period have been released to all registered users selected under the GOSAT research announcement. AIRS V6 $\mathrm{CH}_{4}$ data are used in this study, and they are downloaded from Goddard Earth Sciences Data and Information Services Center (DISC) (http://mirador.gsfc.nasa.gov/cgi-bin/mirador/ presentNavigation.pl?tree=project\&project=AIRS). Only

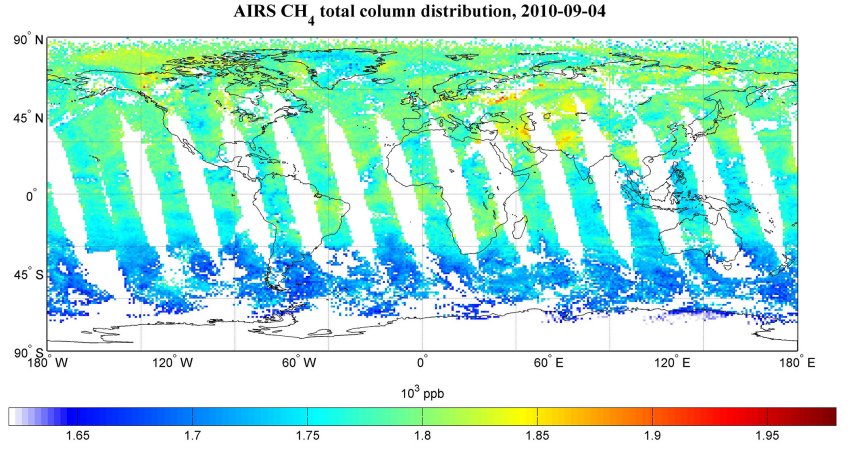

(a)

GOSAT-TIR $\mathrm{CH}_{4}$ total column distribution, 2010-09-04

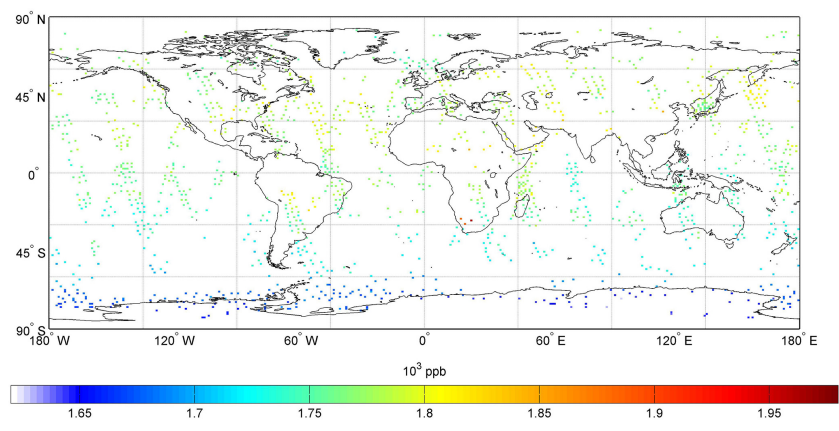

(b)

Figure 1. Much larger coverage of AIRS retrievals (a) as compared to GOSAT TANSO-FTS (b) as shown from the global $\mathrm{CH}_{4}$ total column density on 4 September 2010. AIRS data from ascending mode with $\mathrm{QC}=0,1$ are plotted.

the data from the ascending mode of AIRS, with quality flag equal to 0 or 1 , are used for comparison with GOSAT-TIR. Note that the number of retrieval profiles from AIRS is much denser than GOSAT-TIR, as shown in Fig. 1. In this case, the number of profiles from GOSAT-TIR is 1479 , while the number of the AIRS profiles from ascending node with $\mathrm{QC}=0$ and 1 is 164355 . The AIRS retrievals within $1^{\circ}$ from each GOSAT-TIR measurement and in the same day were averaged to match up with each GOSAT-TIR measurement. The errors resulting from the time difference of about $4 \mathrm{~h}$ between AIRS and GOSAT-TIR observations were not accounted for in this study given that $\mathrm{CH}_{4}$ is a long-lived and well-mixed gas. For simplification, in the comparison of the total column $\mathrm{CH}_{4}$, the AIRS gridded products from NASA DISC in $1^{\circ} \times 1^{\circ}$ were used directly, and the GOSAT-TIR data were interpolated to the same geographical grid as AIRS.

Comparisons between GOSAT-TIR and AIRS $\mathrm{CH}_{4}$ products include (1) $\mathrm{CH}_{4}$ profile comparison, (2) comparison of $\mathrm{CH}_{4}$ mixing ratios with and without using the averaging kernels, and (3) comparison of the column-averaged $\mathrm{CH}_{4}$ and the total column abundance in different latitude zones and different times. The $\mathrm{CH}_{4}$ total column abundance from AIRS 


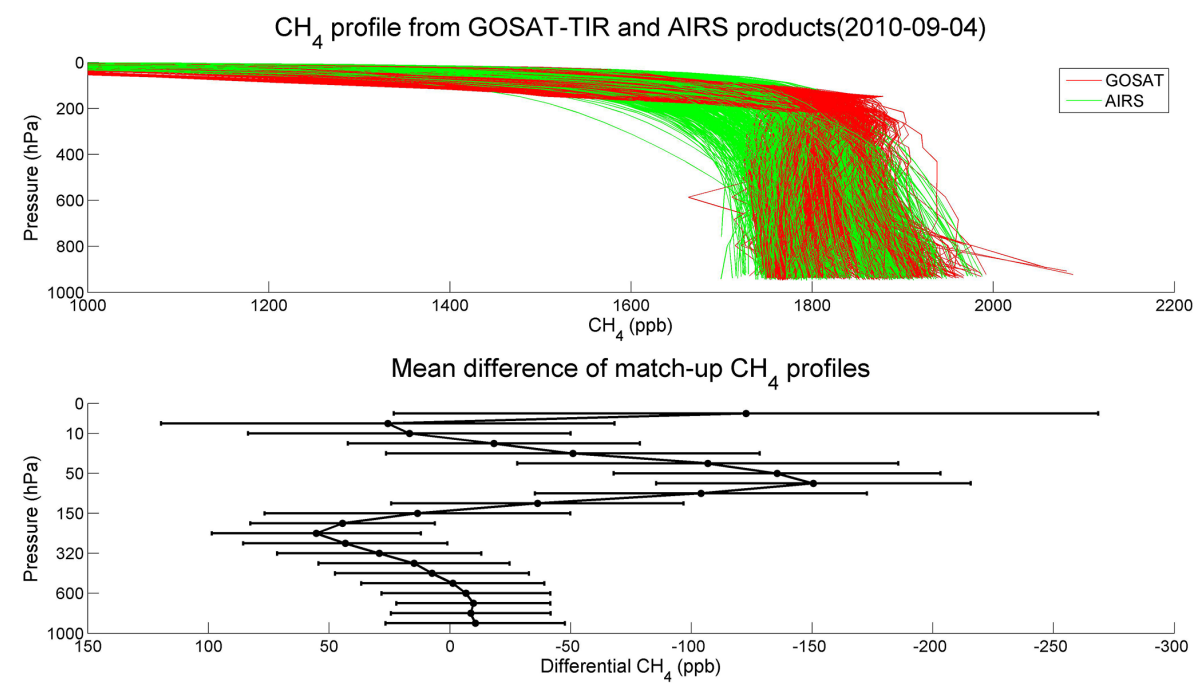

Figure 2. Comparison of the matched-up AIRS $\mathrm{CH}_{4}$ profiles versus the GOSAT-TIR profiles using 1 day of global data on 4 September 2010. $N=1182$. Lower panel is the mean difference of AIRS minus GOSAT profiles.

ascending mode whose unit is molecules $\mathrm{cm}^{-2}$ was used. Since the unit of GOSAT-TIR $\mathrm{CH}_{4}$ profile was ppb, pressure profile $\boldsymbol{P}$ and surface pressure $P_{0}$ are used to convert the unit of GOSAT-TIR $\mathrm{CH}_{4}$ profile. First, pressure gradient is calculated as

$\Delta \boldsymbol{P}_{i}=\boldsymbol{P}_{i+1}-\boldsymbol{P}_{i}$

where $i$ denotes layer number; the formula to calculate Tc is

$\mathrm{Tc}=\sum \Delta \boldsymbol{P}_{i} \cdot \boldsymbol{X}_{i} /\left(P_{0}-P_{\mathrm{T}}\right)$,

where $P_{\mathrm{T}}$ is the top-layer pressure. Pressure profile is included in the GOSAT-TIR product. As a GOSAT TANSOFTS TIR $\mathrm{CH}_{4}$ profile consists of 22 layers, and AIRS-V6 $\mathrm{CH}_{4}$ profile contains 100 layers in the supporting product and 10 layers in the standard product, interpolation of AIRS $\mathrm{CH}_{4}$ profile from 100 layers to 22 layers was made using the pressure data included in both $\mathrm{CH}_{4}$ products.

Later in this paper the "differences" between GOSAT-TIR and $\mathrm{AIRS} \mathrm{CH}_{4}$ are calculated as

$$
\begin{aligned}
& \Delta X=X_{\mathrm{G}}-X_{\mathrm{A}} \\
& \text { Or }\left(X_{\mathrm{G}}-X_{\mathrm{A}}\right) / X_{\mathrm{A}} \times 100 \%,
\end{aligned}
$$

where $X_{\mathrm{G}}$ denotes the $\mathrm{CH}_{4}$ mixing ratios or column amounts from GOSAT-TIR, and $X_{\mathrm{A}}$ from AIRS.

\section{Results}

\subsection{Profile comparison}

Figure 2 shows a simple comparison of the GOSAT-TIR profiles and the coincident AIRS $\mathrm{CH}_{4}$ profiles from 1 day of global data on 4 September 2010. They are in a good agreement above $100 \mathrm{hPa}$ and below $400 \mathrm{hPa}$, with mean difference no more than $50 \mathrm{ppb}$, but at $200-300 \mathrm{hPa}$ AIRS $\mathrm{CH}_{4}$ spans a large range and tends to be smaller than GOSAT TIR on average.

The averaging kernels are defined to provide a characterization of the relationship between the retrieval and the true state. The retrieval sensitivity can be obtained from the sum of the rows of the averaging kernel matrix, which is also referred to as "the area of the averaging kernel" (Rodgers, 2000). To better demonstrate the differences in sensitivities between AIRS and GOSAT-TIR retrievals, Fig. 3 shows an example of the averaging kernels using data at a randomly selected location $\left(38^{\circ} \mathrm{S}, 180^{\circ} \mathrm{W}\right)$ on 4 September 2010 . There are 10 retrieval layers for AIRS and 22 for GOSAT-TIR. The area of the averaging kernels, which is computed as the sum of all individual kernels, from AIRS is larger than that from GOSAT-TIR, as shown in Fig. 3. To demonstrate the sensitivity variations in latitudes, Fig. 4 shows a curtain plot of the area of averaging kernels using 1 day of global data on 4 September 2010. Overall, the patterns from AIRS are similar to GOSAT TIR, with both peak sensitivities located in the 300-600 $\mathrm{hPa}$ range in the high latitudes and $200-600 \mathrm{hPa}$ in the tropics. The sensitivities below $800 \mathrm{hPa}$ are small for both, which reflects the major limitation of TIR in measuring the change of $\mathrm{CH}_{4}$ in the lower troposphere.

The information content, which is usually represented as the DOF, is computed as the trace of the averaging kernel matrix (Rodgers and Connor, 2003). Figure 5 shows the variation of DOFs at different latitudes, and on average the DOF of AIRS $\mathrm{CH}_{4}$ is approximately 1.1, whereas the mean DOF for the GOSAT-TIR retrieval of $\mathrm{CH}_{4}$ is approximately 0.61 . 

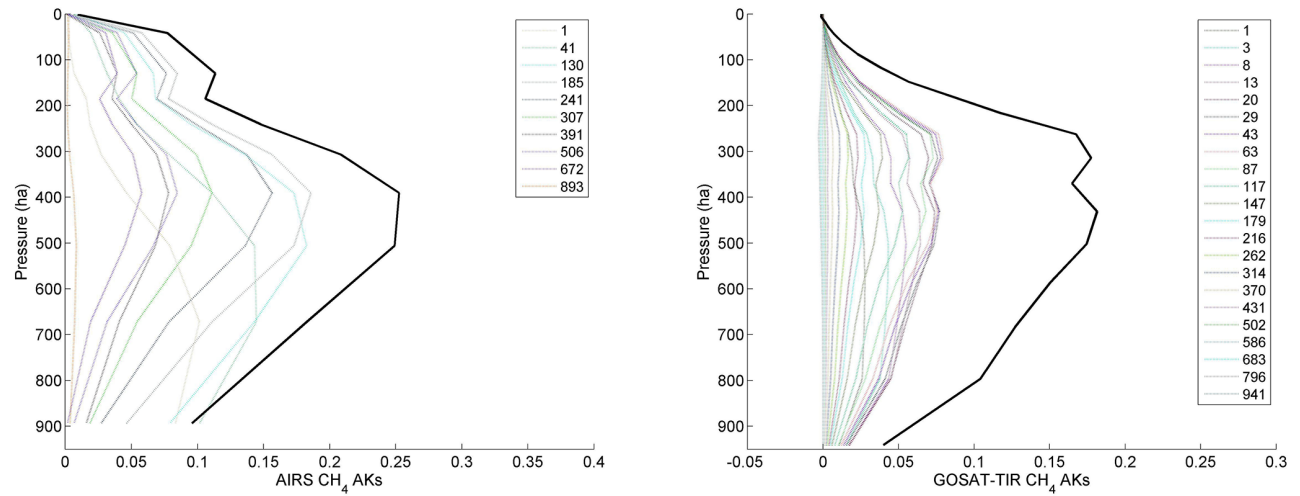

Figure 3. The averaging kernels of AIRS and GOSAT TANSO-FTS TIR V1.0 $\mathrm{CH}_{4}$ retrievals on 4 September 2010 . There are 10 dashed lines for AIRS retrievals and 22 dashed lines for GOSAT retrievals, corresponding to the retrieval layers used in each of them. The black solid line is the area of kernels divided by 4.

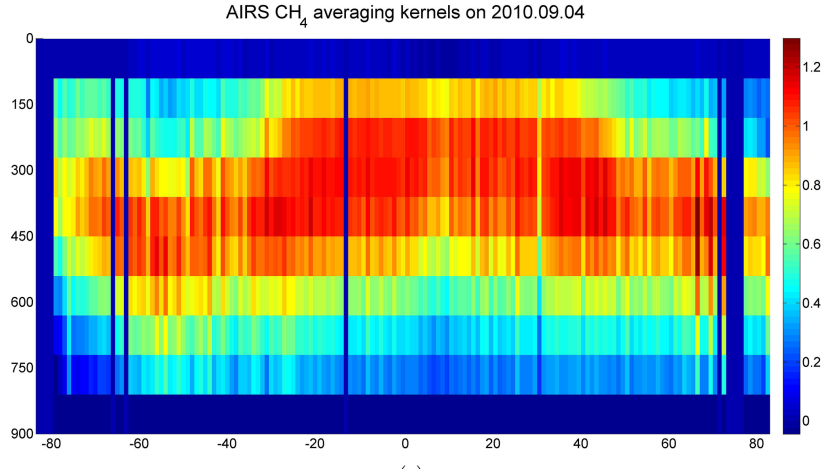

(a)

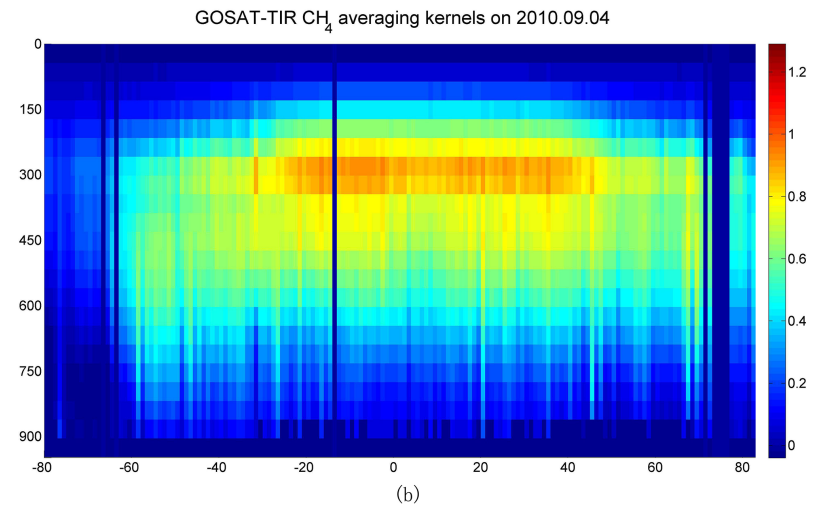

Figure 4. The area of the averaging kernels of $\mathrm{CH}_{4}$ retrievals from (a) AIRS and (b) GOSAT TANSO-FTS V1.0 TIR observations at different latitudes on 4 September 2010.

\subsection{Comparison of $\mathrm{CH}_{4}$ with and without using the averaging kernels}

Since intercomparison is made between two space-based sensors, it is necessary to take account of the different characteristics of the observing systems, particularly their averaging kernels, which is usually applied to the "truth" based

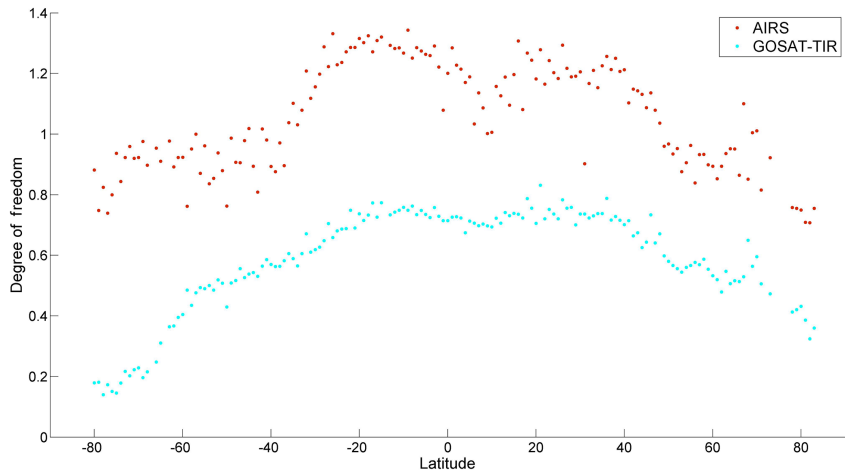

Figure 5. Latitudinal variation of DOF for AIRS and GOSAT TANSO-FTS V1.0 $\mathrm{CH}_{4}$ retrievals on 4 September 2010.

on the following equation (Rodgers and Connor, 2003):

$\hat{\boldsymbol{X}}-\boldsymbol{X}_{\mathrm{c}}=\mathbf{A}\left(\boldsymbol{X}-\boldsymbol{X}_{\mathrm{c}}\right)+\boldsymbol{\epsilon}_{\mathbf{x}}$,

where $\mathbf{A}$ is the averaging kernel. Here we use this equation to calculate the difference between GOSAT-TIR and AIRS $\mathrm{CH}_{4}$. So $\boldsymbol{X}$ represents the true state of $\mathrm{CH}_{4}$ profile; $\boldsymbol{X}_{\mathrm{c}}$ is the mean of comparison ensemble of $\mathrm{CH}_{4}$ profile, and it can be calculated using a regression-based function of latitude and longitude; $\hat{\boldsymbol{X}}$ is the retrieved quantity related to the true profile $\boldsymbol{X}$ and $\boldsymbol{\epsilon}_{x}$ is the error. The computed value of $\hat{\boldsymbol{X}}$ is referred to as the convolved data later in this paper, which is usually compared with the retrieved $\mathrm{CH}_{4}$ mixing ratio in validation studies. Considering that the AIRS retrieval layers are coarser than those of GOSAT-TIR, we used the AIRS averaging kernels, $\mathbf{A}$, to convert the GOSAT-TIR $\mathrm{CH}_{4}$ profiles, $\boldsymbol{X}$, and the convolved (or smoothed) GOSAT-TIR profiles $(\hat{\boldsymbol{X}})$ are then used to derive $\mathrm{CH}_{4}$ total column for comparison. This calculation is based on the Eq. (25) from Rodgers and Connor (2003).

$\hat{c_{12}}=c_{\mathrm{c}}+\boldsymbol{a}_{1}^{\mathbf{T}}\left(\hat{\boldsymbol{X}}-\boldsymbol{X}_{\mathrm{c}}\right)$, 


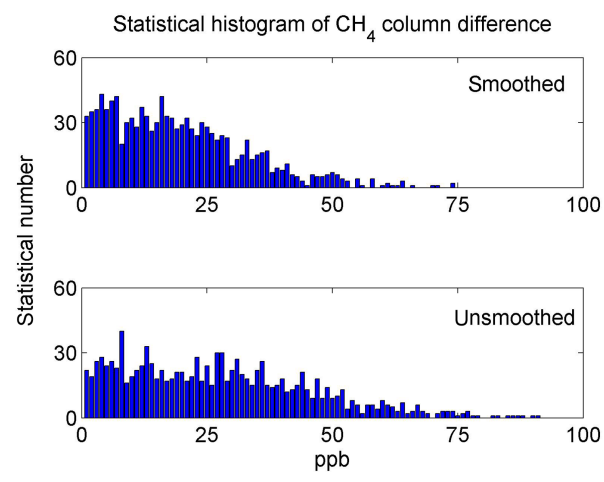

Figure 6. Comparison of AIRS and GOSAT-TIR $\mathrm{CH}_{4}$ matched-pair difference. The upper panel shows the statistical histogram of AIRS $\mathrm{CH}_{4}$ difference to smoothed GOSAT-TIR $\mathrm{CH}_{4}$ and the lower panel shows that to unsmoothed GOSAT-TIR $\mathrm{CH}_{4}$.

where $\boldsymbol{a}_{1}$ is the total column averaging kernel of AIRS $\mathrm{CH}_{4}$; $c_{\mathrm{c}}$ is the total column derived from $\boldsymbol{X}_{\mathrm{c}}$; and $\hat{c_{12}}$ is the related total column using convolved GOSAT-TIR profiles. As the AIRS averaging kernel is a 10 by 10 matrix, the GOSAT-TIR $\mathrm{CH}_{4}$ profile and AIRS first-guess profile are interpolated onto the 10 pressure layers of the AIRS retrieval grid.

Figure 6 shows the distribution of the absolute differences between GOSAT-TIR $\mathrm{CH}_{4}$ and AIRS $\mathrm{CH}_{4}$ column mixing ratios. The upper panel gives the statistical histogram of AIRS $\mathrm{CH}_{4}$ difference to smoothed GOSAT-TIR $\mathrm{CH}_{4}$, while the lower panel shows that to unsmoothed GOSAT-TIR $\mathrm{CH}_{4}$. According to Fig. 6, the number of matched pairs with small differences increases after smoothing. A comparison of the column-averaged mixing ratio, $X_{\mathrm{CH}_{4}}$, in Fig. 7 also shows that the correlation coefficient between AIRS and GOSAT TANSO-FTS TIR retrievals increases from 0.88 to 0.91 after using the smoothed data, and the mean difference decreases from -21.32 to $-2.78 \mathrm{ppb}$. The mean difference and standard deviation between AIRS and the smoothed GOSAT-TIR data are smaller than those without smoothing using the averaging kernels, demonstrating that applying the averaging kernels helps achieve better agreements in the intercomparison between two different measurements, as suggested by Rogers and Connor (2003).

To show the impact of using averaging kernels in the intercomparison, Fig. 8 shows the scatter plot of AIRS versus GOSAT-TIR $\mathrm{CH}_{4}$ mixing ratios in four retrieval layers of 272-343, 343-441, 441-575 and 575-777 $\mathrm{hPa}$. The correlation coefficients between AIRS and the smoothed GOSATTIR values are $0.70,0.70,0.79$ and 0.87 in these four layers respectively, while the correlation coefficients between AIRS and GOSAT-TIR without smoothing are $0.36,0.45,0.57$ and 0.75 respectively.

In next sections, we will focus on the comparison of the total abundance between AIRS and GOSAT-TIR retrievals without applying averaging kernel for smoothing.
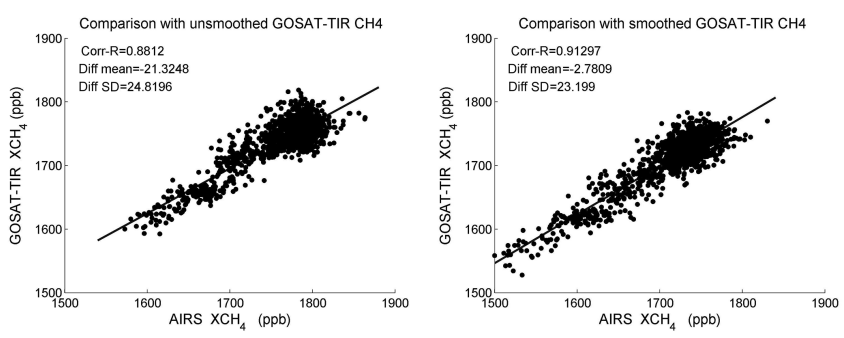

Figure 7. Comparison of $X_{\mathrm{CH}_{4}}$ between AIRS and (a) unsmoothed GOSAT TANSO-FTS TIR $X_{\mathrm{CH}_{4}}$ and (b) smoothed GOSAT-TIR $X_{\mathrm{CH}_{4}}$ using AIRS averaging kernel. Global data on 4 September 2010 are used.
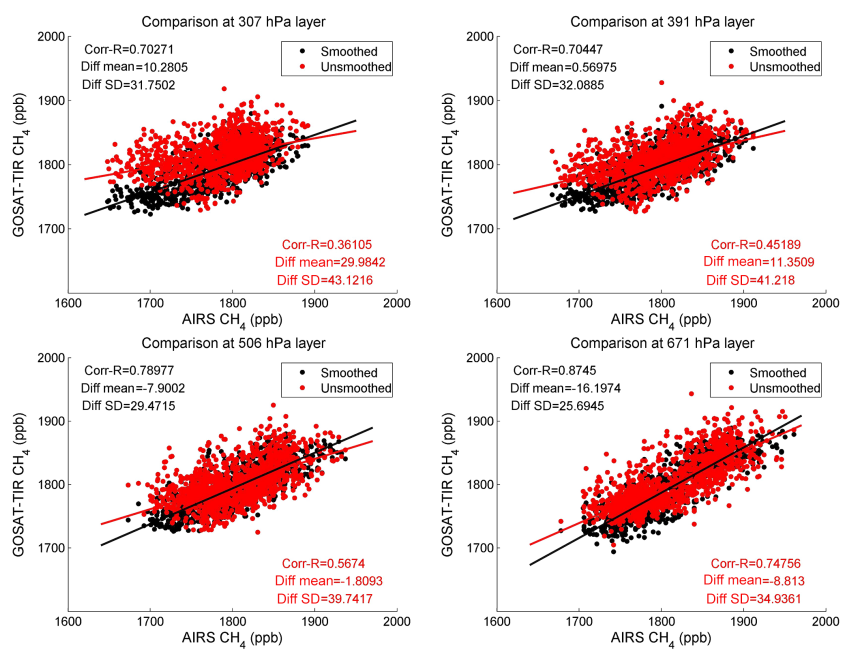

Figure 8. Comparisons of AIRS and GOSAT TANSO-FTS TIR smoothed $\mathrm{CH}_{4}$ at four retrieval pressure levels of $272-343 \mathrm{hPa}$, $343-441 \mathrm{hPa}, 441-575 \mathrm{hPa}$ and $575-777 \mathrm{hPa}$ (the mean effective pressures are 307, 391, 506 and $671 \mathrm{hPa}$ respectively) using 1 day of data on 4 September 2010.

\subsection{Comparison of $\mathrm{CH}_{4}$ total column abundance in different latitude zones}

As the sensitivity of TIR measurements is impacted by the surface thermal contrast and the water vapor content in the atmosphere (Deeter et al., 2007; Xiong et al., 2010b), the sensitivity varies with latitudes and seasons. Below we compare the differences between AIRS and GOSAT TANSO-FTS TIR retrieved total column abundance in six latitude zones from south to north with an interval of $30^{\circ}$. As shown in Figs. 9 and 10, the correlations between AIRS and GOSAT-TIR are reasonably good, and the correlation coefficient for the least correlated case is 0.83 in zone $30-60^{\circ} \mathrm{S}$. The split of $\mathrm{CH}_{4}$ daily comparison is due to these data being located in the high mountains between Chile and Bolivia in South America. This reflects a larger uncertainty in the mountain or coastline regions for AIRS and/or GOSAT. To show the change of their differences with time, Figs. 9 and 10 also show the monthly 

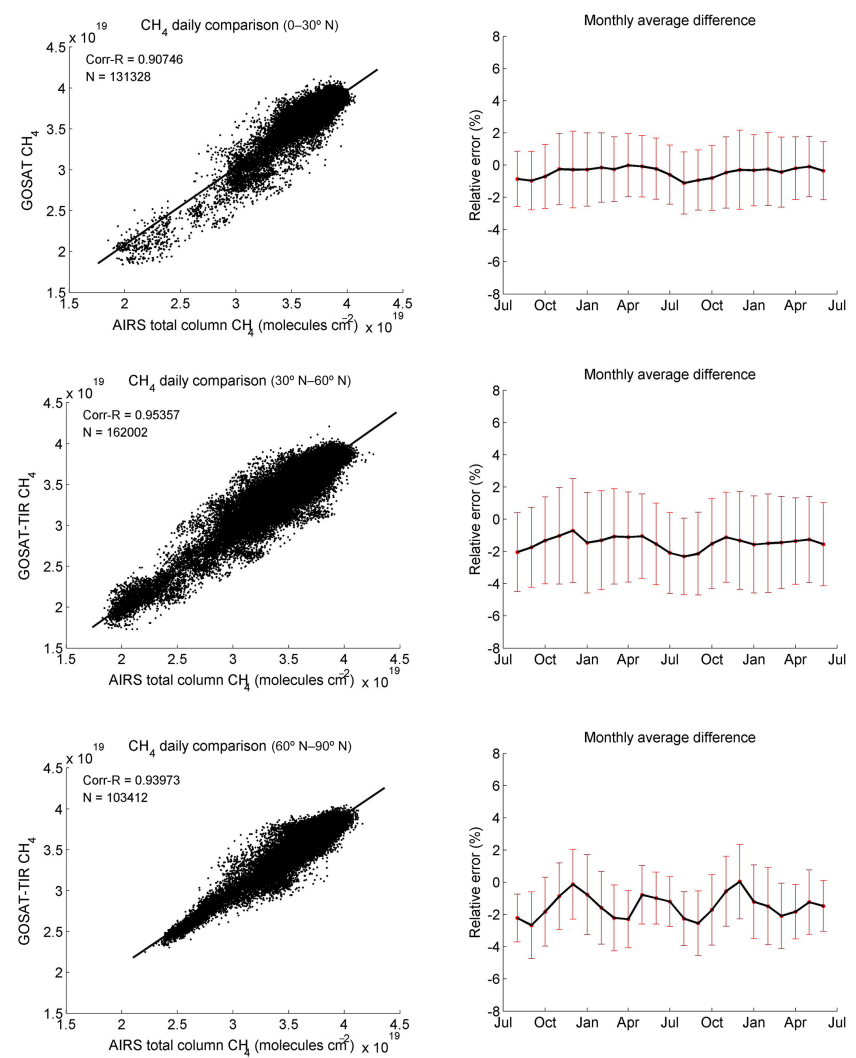

Figure 9. Scatter plot of AIRS versus GOSAT TANSO-FTS TIR $\mathrm{CH}_{4}$ total column density over three latitude zones in the Northern Hemisphere using data from 1 August 2010 to 30 June 2012 (left panels). Right panels show the variation of the mean difference in each month, and the bars are the standard deviation.

means of the differences from August 2010 to June 2012. In the tropics their differences are less than $1 \%$ in all seasons, but in the mid to high latitudes in the Northern Hemisphere, GOSAT-TIR is $\sim 1-2 \%$ lower than AIRS, with the largest bias occurring in September. At high latitudes in the Southern Hemisphere $\left(60-90^{\circ} \mathrm{S}\right)$ the differences of GOSAT from AIRS show a large variation with time, i.e., from $-3 \%$ in October to $+2 \%$ in July. This large difference in the high attitudes in the Southern Hemisphere is related to the very low DOFs, particularly in GOSAT-TIR retrievals (see Fig. 5), and the large uncertainties in the retrieval of atmospheric states when there is snow/ice coverage over the ocean during October to July.

To better show the difference between GOSAT-TIR and AIRS in different latitudes, we computed the mean difference over a 2-year period from 1 August 2010 to 30 June 2012 and in each $15^{\circ}$ zone. As shown in Fig. 11, the standard deviations in the Southern Hemisphere high latitudes are much larger than in the other latitudes, and the mean differences are smaller from $60^{\circ} \mathrm{S}$ to $10^{\circ} \mathrm{N}$ but increase in the Northern Hemisphere to $-1.5 \%$ at $60^{\circ} \mathrm{N}$.
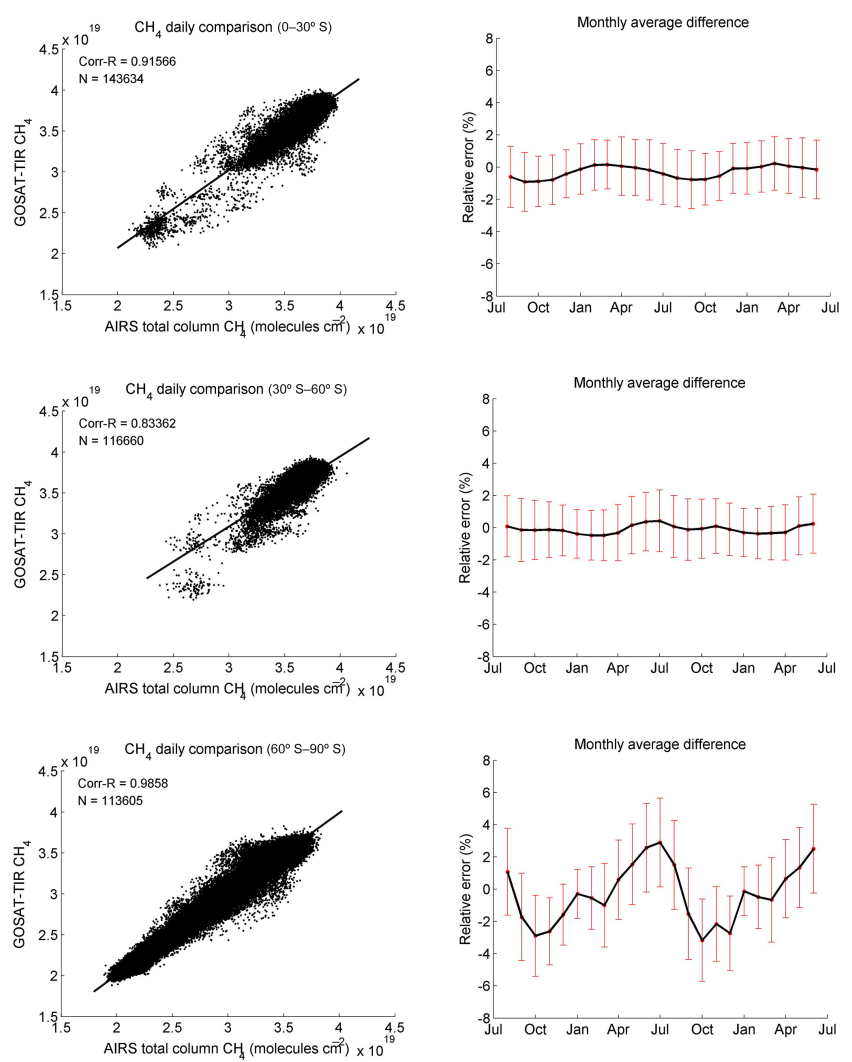

Figure 10. Same as Fig. 8 but for three latitude zones in the Southern Hemisphere.
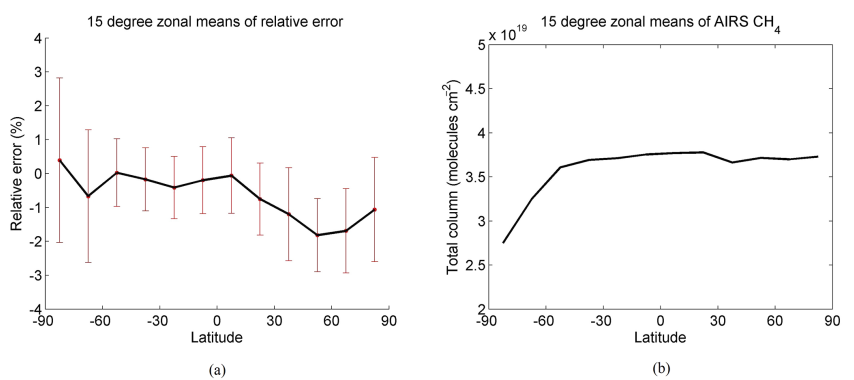

Figure 11. (a) Means of relative errors of GOSAT-TIR total column $\mathrm{CH}_{4}$ relative to AIRS total column $\mathrm{CH}_{4}$ in every $15^{\circ}$ zonal using data from 1 August 2010 to 30 June 2012. (b) $15^{\circ}$ zonal means of AIRS $\mathrm{CH}_{4}$ total column.

\subsection{Comparison of seasonal cycles from AIRS and GOSAT}

Using the monthly averaged total column density of $\mathrm{CH}_{4}$ from AIRS and GOSAT products, we compared the seasonal cycles of $\mathrm{CH}_{4}$ from 1 August 2010 to 30 June 2012. The left panels in Fig. 12 are the comparisons in the Northern Hemisphere, and the right panels are the comparisons in the Southern Hemisphere. Again, GOSAT-TIR agrees with AIRS to within $1 \%$ in the mid-latitude regions of the Southern Hemi- 

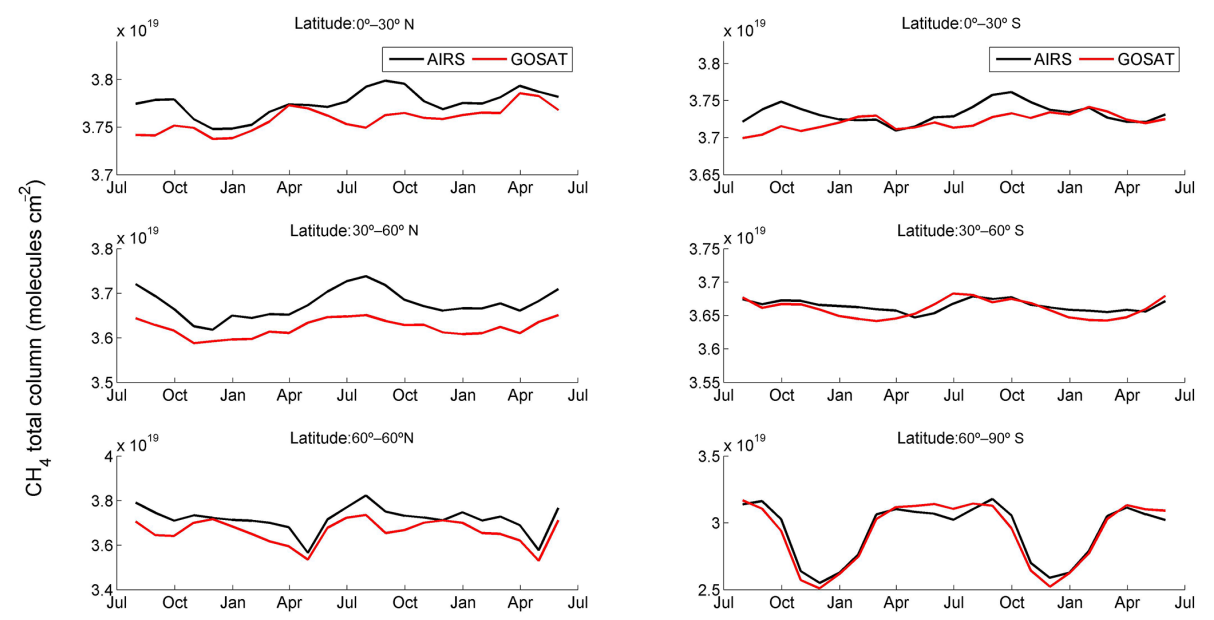

Figure 12. Trends of $\mathrm{CH}_{4}$ monthly averaged total column amounts in different latitudes using AIRS and GOSAT-TIR products from 1 August 2010 to 30 June 2012. The left panels are the comparison in the Northern Hemisphere and the right panels are the comparison in the Southern Hemisphere.

sphere and in the tropics. However, the seasonal variation in the tropics from AIRS observations is larger than that from GOSAT. In the mid to high latitudes in the Northern Hemisphere, GOSAT-TIR is $\sim 1-2 \%$ lower than AIRS, but the seasonal variations agree well. In the high-latitude regions in the Southern Hemisphere, the seasonal variation of the total column of $\mathrm{CH}_{4}$ is large, which is due to a lot of data points with very low total column of $\mathrm{CH}_{4}$ observed during October-January from both AIRS and GOSAT-TIR. However, AIRS and GOSAT agree well in capturing the variation even though their difference is relatively larger than in other regions (see Fig. 10).

\section{Summary and conclusions}

A thorough comparison of AIRS V6 and GOSAT TANSOFTS TIR V1.0 $\mathrm{CH}_{4}$ products using 2 years of data (1 August 2010 to 30 June 2012) has been made. In this comparison, AIRS measurements within a collocation window of $1^{\circ}$ by $1^{\circ}$ from each GOSAT-TIR measurement in the same day were used. Both the $\mathrm{CH}_{4}$ mixing ratios and total column amounts have been compared. To understand the differences in the retrievals from these two different instruments, we also compared the differences in the averaging kernels and the DOFs and examined the use of averaging kernels on the comparison results.

The peak sensitive layers of AIRS and GOSAT-TIR are at similar height, which is at $200-600 \mathrm{hPa}$ in the tropics and $300-600 \mathrm{hPa}$ in the high-latitude regions. However, due to the lower SNR of GOSAT TANSO-FTS spectra in the 7$8 \mu \mathrm{m} \mathrm{CH}_{4}$ band, or over-constraint in the GOSAT retrieval algorithm, the DOF of GOSAT-TIR V1.0 retrievals is lower than AIRS.
The comparisons of the profiles showed that the AIRS $\mathrm{CH}_{4}$ is similar to GOSAT-TIR $\mathrm{CH}_{4}$, except that the AIRS values tend to be lower than GOSAT-TIR at $200-300 \mathrm{hPa}$. At $300 \mathrm{hPa}$, the $\mathrm{CH}_{4}$ mixing ratios from GOSAT are $10.3 \pm 31.8 \mathrm{ppbv}$ higher than AIRS, and at $600 \mathrm{hPa}$, the GOSAT-TIR $\mathrm{CH}_{4}$ is $-16.2 \pm 25.7 \mathrm{ppb}$ lower than AIRS. Between 300 and $600 \mathrm{hPa}$, where they have peak sensitivities, AIRS and GOSAT-TIR agree very well. As expected, applying the averaging kernels to smooth the GOSAT-TIR retrievals results in a better agreement between GOSAT with AIRS products.

The comparison of the total column amounts of $\mathrm{CH}_{4}$ shows that the correlation coefficients between AIRS and GOSAT TANSO-FTS TIR are more than 0.8 in all cases, and the GOSAT-TIR $\mathrm{CH}_{4}$ agrees with AIRS to within $1 \%$ in the mid-latitudes of the Southern Hemisphere and tropics, but in the mid to high latitudes of the Northern Hemisphere, GOSAT-TIR is $\sim 1-2 \%$ lower than AIRS depending on different seasons. In the high latitudes of the Southern Hemisphere the bias varies from $-3 \%$ in October to $+2 \%$ in July. This large difference in high-latitude regions is associated with the low information content (or DOFs) and larger uncertainties in the retrievals of both AIRS (Xiong et al., 2015) and GOSAT. Thus a much stricter quality control should be used as suggested by Xiong et al. (2015). We also found AIRS and GOSAT-TIR have a good agreement in capturing the monthly variation of $\mathrm{CH}_{4}$ density.

In this study, the time difference between AIRS and GOSAT-TIR measurements has not been taken into account. So, the differences, if they could have been measured at the same time, could be slightly smaller than what we presented here. These results demonstrate that the thermal infrared sensors such as AIRS and GOSAT TANSO-FTS TIR can provide valuable consistent information of $\mathrm{CH}_{4}$ in the mid-upper 
troposphere. Further comparisons using more recent data as well as direct comparison with aircraft measurements are ongoing.

\section{Data availability}

The data set of AIRS V6 $\mathrm{CH}_{4}$ product used in this study is available at Goddard Earth Sciences Data and Information Services Center (DISC) (http: //mirador.gsfc.nasa.gov/cgi-bin/mirador/presentNavigation. pl?tree=project\&project=AIRS). And the GOSAT TANSO-FTS TIR Level $2 \mathrm{CH}_{4}$ product can be freely download at GOSAT user interface gateway (GUIG) (https://data.gosat.nies.go.jp/GosatUserInterfaceGateway/ guig/GuigPage/open.do).

Acknowledgements. This work was supported by the Key Program of the National Natural Science Foundation of China (no. 41130528), National Natural Science Foundation of China (nos. 41401387 and 41201353). This study was performed within the framework of the GOSAT Research Announcement.

Edited by: J. Worden

Reviewed by: three anonymous referees

\section{References}

Aumann, H. H., Chahine, M. T., Gautier, C., Goldberg, M. D., Kalnay, E., McMillin, L. M., Revercomb, H., Rosenkranz, P. W., Smith, W. L., Staelin, D. H., Strow, L. L., and Susskind, J.: AIRS/AMSU/HSB on the aqua mission: Design, science objectives, data products, and processing systems, IEEE Trans. Geosci. Remote S., 41, 253-264, 2003.

Baldridge, A. M., Hook, S. J., Grove, C. I., and Rivera, G.: The ASTER Spectral Library Version 2.0., Remote Sens. Environ., 114, 711-715, 2009.

Crevoisier, C., Nobileau, D., Fiore, A. M., Armante, R., Chédin, A., and Scott, N. A.: Tropospheric methane in the tropics - first year from IASI hyperspectral infrared observations, Atmos. Chem. Phys., 9, 6337-6350, doi:10.5194/acp-9-6337-2009, 2009.

Crevoisier, C., Nobileau, D., Armante, R., Crépeau, L., Machida, T., Sawa, Y., Matsueda, H., Schuck, T., Thonat, T., Pernin, J., Scott, N. A., and Chédin, A.: The 2007-2011 evolution of tropical methane in the mid-troposphere as seen from space by MetOpA/IASI, Atmos. Chem. Phys., 13, 4279-4289, doi:10.5194/acp13-4279-2013, 2013.

Deeter, M. N., Edwards, D. P., Gille, J. C., and Drummond, J. R.: Sensitivity of MOPITT observations to carbon monoxide in the lower troposphere, J. Geophys. Res., 112, D24306, doi:10.1029/2007JD008929, 2007.

Frankenberg, C., Bergamaschi, P., Butz, A., Houweling, S., Meirink, J. F., Notholt, J., Petersen, A. K., Schrijver, H., Warneke, T., and Aben, I.: Tropical methane emissions: A revised view from SCIAMACHY onboard ENVISAT, Geophys. Res. Lett., 35, L15811, doi:10.1029/2008GL034300, 2008.
Frankenberg, C., Aben, I., Bergamaschi, P., Dlugokencky, E. J., Van Hees, R., Houweling, S., Van der Meer, P., Snel, R., and Tol, P.: Global column-averaged methane mixing ratios from 2003 to 2009 as derived from sciamachy: Trends and variability, J. Geophys. Res., 116, D04302, doi:10.1029/2010JD014849, 2011.

Goddard Earth Sciences Data and Information Services Center (DISC): AIRS V6 $\mathrm{CH}_{4}$ product, available at: http://mirador.gsfc.nasa.gov/cgi-bin/mirador/presentNavigation. pl?tree=project\&project=AIRS, last access: 2 August 2016.

GOSAT user interface gateway (GUIG): GOSAT TANSO-FTS TIR Level $2 \mathrm{CH}_{4}$ product, available at: https://data.gosat.nies.go. jp/GosatUserInterfaceGateway/guig/GuigPage/open.do, last access: 24 May 2014.

Illingworth, S. M., Allen, G., Newman, S., Vance, A., Marenco, F., Harlow, R. C., Taylor, J., Moore, D. P., and Remedios, J. J.: Atmospheric composition and thermodynamic retrievals from the ARIES airborne FTS system - Part 1: Technical aspects and simulated capability, Atmos. Meas. Tech., 7, 1133-1150, doi:10.5194/amt-7-1133-2014, 2014.

IPCC: Climate Change 2013: The Physical Science Basis, Working Group I Contribution to the Fifth Assessment Report of the Intergovernmental Panel on Climate Change, edited by: Stocker, T. F., Qin, D., Plattner, G.-K., Tignor, M., Allen, S. K., Boschung, J., Nauels, A., Xia, Y., Bex, V., and Midgey, P. M., Cambridge University Press, Cambridge, United Kingdom and New York, NY, USA, 1535 pp., 2013.

Kuze, A., Suto, H., Nakajima, M., and Hamazaki, T.: Thermal and near infrared sensor for carbon observation Fourier-transform spectrometer on the Greenhouse Gases Observing Satellite for greenhouse gases monitoring, Appl. Optics, 48, 6716-6733, 2009.

Kuze, A., Suto, H., Shiomi, K., Urabe, T., Nakajima, M., Yoshida, J., Kawashima, T., Yamamoto, Y., Kataoka, F., and Buijs, H.: Level 1 algorithms for TANSO on GOSAT: processing and on-orbit calibrations, Atmos. Meas. Tech., 5, 2447-2467, doi:10.5194/amt-5-2447-2012, 2012.

Maksyutov, S., Patra, P. K., Onishi, R., Saeki, T., and Nakazawa, T.: NIES/FRCGC global atmospheric tracer transport model: Description, validation, and surface sources and sinks inversion, Journal of the Earth Simulator, 9, 3-18, 2008.

Parker, R., Boesch, H., Cogan, A., Fraser, A., Feng, L., Palmer, P. I., Messerschmidt, J., Deutscher, N., Griffith, D. W. T., Notholt, J., Wennberg, P. O., and Wunch, D.: Methane observations from the Greenhouse Gases Observing SATellite: Comparison to groundbased TCCON data and model calculations, Geophys. Res. Lett., 38, L15807, doi:10.1029/2011GL047871, 2011.

Payne, V. H., Clough, S. A., Shephard, M. W., Nassar, R., and Logan, J. A.: Information-centered representation of retrievals with limited degrees of freedom for signal: Application to methane from the tropospheric emission spectrometer, J. Geophys. Res., 114, D10307, doi:10.1029/2008JD010155, 2009.

Razavi, A., Clerbaux, C., Wespes, C., Clarisse, L., Hurtmans, D., Payan, S., Camy-Peyret, C., and Coheur, P. F.: Characterization of methane retrievals from the IASI space-borne sounder, Atmos. Chem. Phys., 9, 7889-7899, doi:10.5194/acp-9-7889-2009, 2009.

Rodgers, C. D.: Inverse methods for atmospheric sounding: Theory and Practic, World Scientific Publishing Co. Pte. Ltd, Singapore, ISBN-10: 981-02-2740-X, 2000. 
Rodgers, C. D. and Connor, B. J.: Intercomparison of remote sounding instruments, J. Geophys. Res., 108, 4116, doi:10.1029/2002JD002299, 2003.

Saeki, T., Saito, R., Belikov, D., and Maksyutov, S.: Global highresolution simulations of $\mathrm{CO}_{2}$ and $\mathrm{CH}_{4}$ using a NIES transport model to produce a priori concentrations for use in satellite data retrievals, Geosci. Model Dev., 6, 81-100, doi:10.5194/gmd-681-2013, 2013.

Saitoh, N., Imasu, R., Ota, Y., and Niwa, Y.: $\mathrm{CO}_{2}$ retrieval algorithm for the thermal infrared spectra of theGreenhouse Gases Observing Satellite: Potential of retrieving $\mathrm{CO}_{2}$ vertical profile from high-resolution FTS sensor, J. Geophys. Res., 114, D17305, doi:10.1029/2008JD011500, 2009.

Saitoh, N., Touno, M., Hayashida, S., Imasu, R., Shiomi, K., Yokota, T., Yoshida, Y., Machida, T., Matsueda, H., and Sawa, Y.: Comparisons between $X_{\mathrm{CH}_{4}}$ from GOSAT Shortwave and Thermal Infrared Spectra and Aircraft $\mathrm{CH}_{4}$ Measurements over Guam, Scientific Online Letters on the Atmosphere, 8, 145-149, doi:10.2151/sola.2012-036, 2012.

Saitoh, N., Kimoto, S., Sugimura, R., Imasu, R., Kawakami, S., Shiomi, K., Kuze, A., Machida, T., Sawa, Y., and Matsueda, H.: Algorithm update of the GOSAT/TANSO-FTS thermal infrared $\mathrm{CO}_{2}$ product (version 1) and validation of the UTLS $\mathrm{CO}_{2}$ data using CONTRAIL measurements, Atmos. Meas. Tech., 9, 21192134, doi:10.5194/amt-9-2119-2016, 2016.

Schepers, D., Guerlet, S., Butz, A., Landgraf, J., Frankenberg, C., Hasekamp, O., Blavier, J. F., Deutscher, N. M., Griffith, D. W. T., Hase, F., Kyro, E., Morino, I., Sherlock, V., Sussmann, R., and Aben, I.: Methane retrievals from Greenhouse Gases Observing Satellite (GOSAT) shortwave infrared measurements: Performance comparison of proxy and physics retrieval algorithms, J. Geophys. Res., 117, D10307, doi:10.1029/2012jd017549, 2012.

Tans, P. P.: The atmospheric buildup rate for carbon is based on measurements of $\mathrm{CO}_{2}$ at Mauna Loa obtained by the NOAA Earth System Research Laboratory, available at: ftp: //aftp.cmdl.noaa.gov/products/trends/co2/co2_gr_mlo.txt, www. esrl.noaa.gov/gmd/ccgg/trends/ (last access: 5 October 2015), 2009.
Wecht, K. J., Jacob, D. J., Wofsy, S. C., Kort, E. A., Worden, J. R., Kulawik, S. S., Henze, D. K., Kopacz, M., and Payne, V. H.: Validation of TES methane with HIPPO aircraft observations: implications for inverse modeling of methane sources, Atmos. Chem. Phys., 12, 1823-1832, doi:10.5194/acp-12-1823-2012, 2012.

Worden, J., Kulawik, S., Frankenberg, C., Payne, V., Bowman, K., Cady-Peirara, K., Wecht, K., Lee, J.-E., and Noone, D.: Profiles of $\mathrm{CH}_{4}, \mathrm{HDO}, \mathrm{H}_{2} \mathrm{O}$, and $\mathrm{N}_{2} \mathrm{O}$ with improved lower tropospheric vertical resolution from Aura TES radiances, Atmos. Meas. Tech., 5, 397-411, doi:10.5194/amt-5-397-2012, 2012.

Xiong, X., Barnet, C., Maddy, E., Sweeney, C., Liu, X., Zhou, L., and Goldberg, M.: Characterization and validation of methane products from the Atmospheric Infrared Sounder (AIRS), J. Geophys. Res., 113, G00A01, doi:10.1029/2007JG000500, 2008.

Xiong, X., Barnet, C., Maddy, E., Wei, J., Liu, X., and Pagano, T. S.: Seven Years' Observation of Mid-Upper Tropospheric Methane from Atmospheric Infrared Sounder, Remote Sens., 2, 25092530, 2010a.

Xiong, X., Barnet, C. D., Zhuang, Q., Machida, T., Sweeney, C., and Patra, P. K.: Mid-upper tropospheric methane in the high Northern Hemisphere: Spaceborne observations by AIRS, aircraft measurements, and model simulations, J. Geophys. Res., 115, D19309, doi:10.1029/2009JD013796, 2010b.

Xiong, X., Barnet, C., Maddy, E. S., Gambacorta, A., King, T. S., and Wofsy, S. C.: Mid-upper tropospheric methane retrieval from IASI and its validation, Atmos. Meas. Tech., 6, 2255-2265, doi:10.5194/amt-6-2255-2013, 2013.

Xiong, X., Weng, F., Liu, Q., and Olsen, E.: Space-borne observation of methane from atmospheric infrared sounder version 6 : validation and implications for data analysis, Atmos. Meas. Tech. Discuss., 8, 8563-8597, doi:10.5194/amtd-8-8563-2015, 2015.

Yokota, T., Yoshida, Y., Eguchi, N., Ota, Y., Tanaka, T., Watanabe, H., and Maksyutov, S.: Global Concentrations of $\mathrm{CO}_{2}$ and $\mathrm{CH}_{4}$ Retrieved from GOSAT: First Preliminary Results, SOLA, 5, 160-163, 2009. 